\title{
An approach for evaluation of grading forecasting index of coal spontaneous combustion by temperature-programmed analysis
}

Kai Wang ( $\square$ wangk912@xust.edu.cn)

Xi'an University of Science and Technology https://orcid.org/0000-0001-5667-9073

Yang Li

Xi'an University of Science and Technology

Yanni Zhang

Xi'an University of Science and Technology

Jun Deng

Xi'an University of Science and Technology

\section{Research Article}

Keywords: Coal spontaneous combustion, Particle size, Grading forecasting index, Coefficient of variation, Weighted grey relational analysis

Posted Date: February 23rd, 2022

DOI: https://doi.org/10.21203/rs.3.rs-1271303/v1

License: (c) (i) This work is licensed under a Creative Commons Attribution 4.0 International License. Read Full License 


\title{
An approach for evaluation of grading forecasting index of coal spontaneous combustion by temperature-programmed analysis
}

\author{
Kai Wang ${ }^{1,2, *}$, Yang Li ${ }^{1,2}$, Yanni Zhang ${ }^{1,2}$, Jun Deng ${ }^{1,2}$ \\ (1. College of Safety Science and Engineering, Xi'an University of Science and Technology, Xi'an \\ 710054, China; 2. Shaanxi Key Laboratory of Prevention and Control of Coal Fire, Xi'an 710054,
}

\section{China)}

*Corresponding authors.

\section{Kai Wang}

E-mail address: wangk912@xust.edu.cn

\section{Acknowledgements}

This work was supported by The Youth Innovation Team of Shaanxi Universities (21JP070), the National Natural Science Foundation of China (No. 52174199, 51974236), and the Key R\&D Program of Shaanxi Province (Grant No. 2021KW-11).

\section{Abstract}

Focused on the prediction and forecast index of coal spontaneous combustion, the temperature-programmed experiments were carried out to identify the releasing rule of the gaseous compounds with the consideration of coal particle sizes. Based on the method of growth rate analysis, critical and dry cracking temperature temperatures were determined, dividing the coal low-temperature oxidation process into three stages. The critical temperature for the spontaneous combustion of the coal is in the range of $60^{\circ} \mathrm{C} \sim 70^{\circ} \mathrm{C}$, with the dry cracking temperature ranging from $100^{\circ} \mathrm{C}$ to $110^{\circ} \mathrm{C}$. It was 
found that the particle sizes had obvious effects on the release of gaseous compounds during the coal heating test. To reduce the influence of coal particle size on the forecasting of coal spontaneous combustion, the combination methods of coefficient of variation and the weighted grey relational analysis were proposed for the selection and evaluation of coal spontaneous combustion indexes. For the tested coal sample, $\mathrm{CO}_{2} / \mathrm{CO}$ was selected as the first index, $\mathrm{O}_{2} /\left(\mathrm{CO}+\mathrm{CO}_{2}\right)$ and $\mathrm{CO}_{2} / \mathrm{O}_{2}$ as the second index. $\mathrm{C}_{2} \mathrm{H}_{4}$ and $\mathrm{C}_{2} \mathrm{H}_{6}$ were selected as the index gases to confirm that the coal oxidation reached the dry cracking temperature. This research could provide a reference for the determination of the grading forecasting index of coal spontaneous combustion.

Keywords: Coal spontaneous combustion; Particle size; Grading forecasting index; Coefficient of variation; Weighted grey relational analysis 


\section{Introduction}

Coal spontaneous combustion is one of the major disasters that threaten the safe production of coal mines (Taraba and Michalec 2011; Kong et al. 2017). It not only causes wastage of resources (Shao et al. 2015; Wang et al. 2018a; Li et al. 2016), but also leads to gas and coal dust explosions, which threaten the health of mineworkers seriously. In addition, hazardous gas, as well as greenhouse gases, are generated (Wang et al. 2016; $\mathrm{Xu}$ et al. 2018; Honscha et al. 2021), thus, causing significant damage to the atmosphere and ecological environment (Wang et al. 2018b; Zhang et al. 2016; Song and Kuenzer 2014). Accurate prediction and forecasting are important to control the hazard of coal spontaneous combustion (Onifade and Genc 2020; Qu 2018). In this respect, the determination of the quantitative index to predict and forecast the coal spontaneous combustion in a complex environment becomes a research hotspot (Yuan and Smith 2011; Baris et al. 2012).

During the coal spontaneous combustion, various gas products are released, and their concentrations are positively correlated with coal temperature (Ma et al. 2019). These gases are usually used to predict and forecast coal spontaneous combustion, which is very important for mine safety (Deng et al. 2014a, 2015). Guo et al. (2019a) assessed the qualitative and quantitative analysis of the $\mathrm{CO}$ and $\mathrm{C}_{2} \mathrm{H}_{4}$ formation rates, as well as various gas ratios to forecast coal spontaneous combustion. Deng et al. (2014b) proposed the growth rate analysis method to identify the characteristic temperature of spontaneous combustion. Guo et al. (2019b) found that the olefin index gas can predict coal spontaneous combustion more accurately than alkane index gas in low oxygen 
concentration conditions. Wen et al. (2017a) designed and manufactured the XKGW-1 type high-temperature experimental device to study the influence of the oxygen concentration on the characteristic of coal spontaneous combustion. Wen et al. (2017b) made a forecast model for the concentration of $\mathrm{CO}$ at the air return corner under coal mine, which can be can be used to precisely evaluate the degree of coal spontaneous combustion. Ma et al. (2020) proposed a new index D-O to forecast the coal temperature during the process of coal spontaneous combustion. Zhai et al. (2021) used thermogravimetry to determine characteristic temperatures to judge low-temperature oxidation stages of water-immersion coal.

Coal spontaneous combustion is a highly compound procedure. The characteristics of coal spontaneous combustion are mainly studied from two scales: micro and macro (Wang et al. 2021; Deng et al. 2018; Fan et al. 2021). The particle size is one of the main external factors affecting coal spontaneous combustion (Zhang et al. 2019; Yi et al. 2014a; Yi et al. 2014b). The smaller particle size could facilitate occurrence of coal spontaneous combustion (Fernandez-Anez and Garcia-Torrent 2019), enhancing the oxidizability and exothermicity of coal spontaneous combustion and releasing more gas production (Deng et al. 2017). Zhang et al. (2018) conducted laboratory experiments of coal spontaneous combustion under non-isothermal conditions, and the consequence showed that the total $\mathrm{CO}$ output of small particle size coal is more than that of larger particle size coal. Luo et al. (2019) pointed out that, as the particle size decreases, the content of $\mathrm{CO}$, light hydrocarbons, and $\mathrm{NO}_{\mathrm{x}}$ precursors all showed a tendency of decrease after the increase during rapid pyrolysis of coal. Rifella et al. (2019) conducted 
a comprehensive analysis of the crossing-point temperature and critical self-ignition temperature and found that larger particles have a lower risk of spontaneous combustion.

The integral characteristic of the low-temperature gas-phase ignition of the products of the thermal decomposition of coal particles is determined (Glushkov et al. 2015). Qin et al. (2012) proposed the oxygen consumption rate equation of coal samples with the mixed particle size, which can be used to accurately calculate the true oxygen consumption rate of coal samples. Jia et al. (2021) found that the smaller particle size of coal improves the adsorption capacity of coal and oxygen molecules, and boosts the oxygen consumption rate.

To sum up, the particle size could affect the production of gas during the process of coal-oxygen compound reaction, also affects the accuracy selection of coal spontaneous combustion indexes. To reduce the effects of particle size on predictive index of spontaneous combustion, the coefficient of variation and weighted grey relational analysis were combined to evaluate the accuracy of grading foracast of coal spontaneous combustion index by the temperature-programmed experiments in this study. 


\section{Experimental Methodology}

\subsection{Coal samples}

The coal sample used in this study was collected from the Lu'an mining area in Shanxi

Province, China. Being crushed in a dry environment, the coal samples in the partical size ranges of $0 \sim 0.9 \mathrm{~mm}, 0.9 \sim 3 \mathrm{~mm}, 3 \sim 5 \mathrm{~mm}, 5 \sim 7 \mathrm{~mm}$, and $7 \sim 10 \mathrm{~mm}$ were sieved. A one-kilogram mixed coal sample was prepared by mixing 200 grams from each of the five partical sizes.

\subsection{Experimental device}

This study employed the temperature-programmed experimental system developed by Xi'an University of Science and Technology. The experimental device consisted of four parts: gas channel, temperature control box, gas collection area, and gas chromatograph. The temperature-programmed experimental system was shown in Fig. 1.

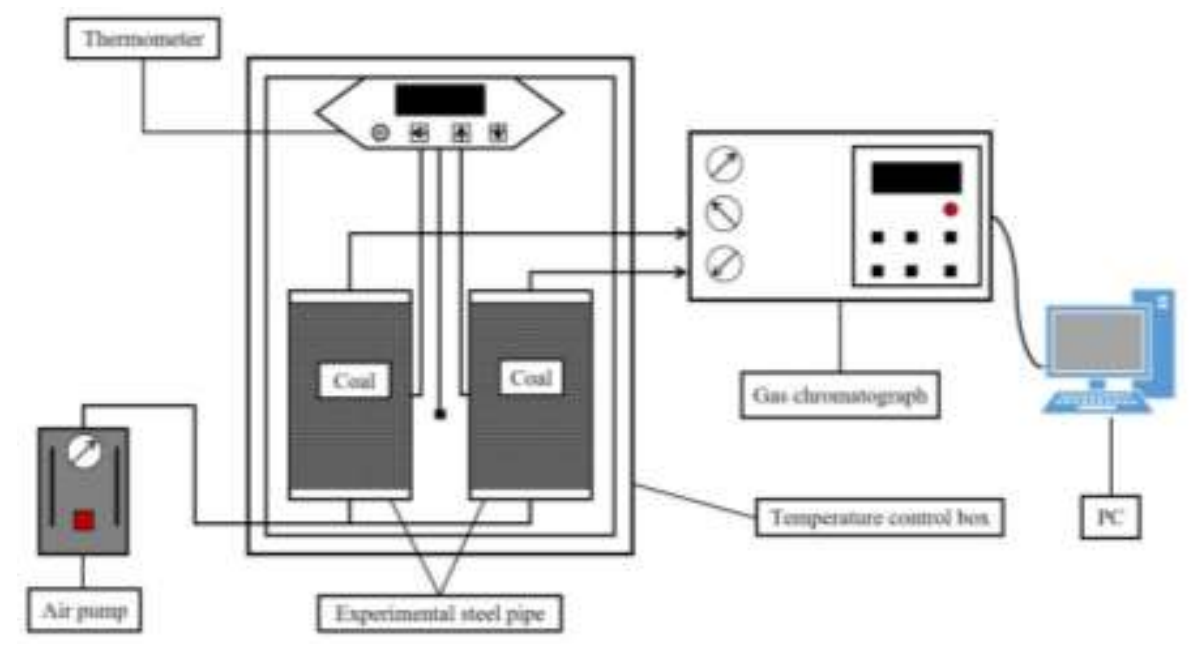

Fig. 1 XK temperature-programmed experimental system

\subsection{Experimental process}

The coal sample was placed in an experimental steel pipe with a diameter of $10 \mathrm{~cm}$ and a length of $22 \mathrm{~cm}$. To ventilate evenly, leave a space of about $2 \mathrm{~cm}$ at the upper and 
111 lower ends (using 100 mesh copper wire to fix the coal sample), and then ensure the

112 airtightness of the gas path. The steel pipe was put in the temperature-programmed box

113 and injected to preheated air, followed by the collection of gases generated at different

114 coal temperatures. During the experiment, the heating rate of the coal body was

115 controlled to be $0.3^{\circ} \mathrm{C} / \mathrm{min}$, and the airflow rate was $120 \mathrm{ml} / \mathrm{min}$. Heating from $30^{\circ} \mathrm{C}$ to

$116170^{\circ} \mathrm{C}$, the composition and concentration of the collected gases were analyzed by gas

117 chromatography every $10^{\circ} \mathrm{C}$ during the heating process.

\section{3. Results and discussion}

\subsection{Characteristic temperature}

120 Critical temperature and dry cracking temperature are two important characteristic

121 temperatures in the process of coal spontaneous combustion. They could be used to

122 judge the degree of coal oxidation, which provides a basis for the early grading forecast

123 of coal spontaneous combustion (Xiao et al. 2017; Hu and Xia 2017). As the oxygen

124 consumption rate is one of the crucial factors affecting coal self-heating capacity (Zhu

125 et al. 2012), it can precisely correspond to the degree of coal spontaneous combustion.

126 Therefore, in this study, the growth rate of oxygen consumption rate with temperature

127 was used to determine the characteristic temperatures of coal spontaneous combustion

128 (Deng et al. 2014b; Zhao et al. 2019). The equation of the growth rate is as follows:

$$
B=\frac{c_{i+1}-c_{i}}{t_{i+1}-t_{i}}
$$

130 Where $c$ is the oxygen consumption rate, $t$ is the temperature and $B$ is the gradient of

131 oxygen consumption rate as the temperature rises by $1^{\circ} \mathrm{C}$. 


$$
Z=\frac{B}{c_{i}}
$$

133 Where $Z$ is the growth rate of oxygen consumption rate at a temperature of $t_{i+1}$.

134 From Eqs. (1) and (2), Eq. (3) can be obtained:

$$
Z=\frac{c_{i+1}-c_{i}}{c_{i}\left(t_{i+1}-t_{i}\right)}
$$

Fig. 2 shows the curve of oxygen consumption rate with temperature for the coal samples.

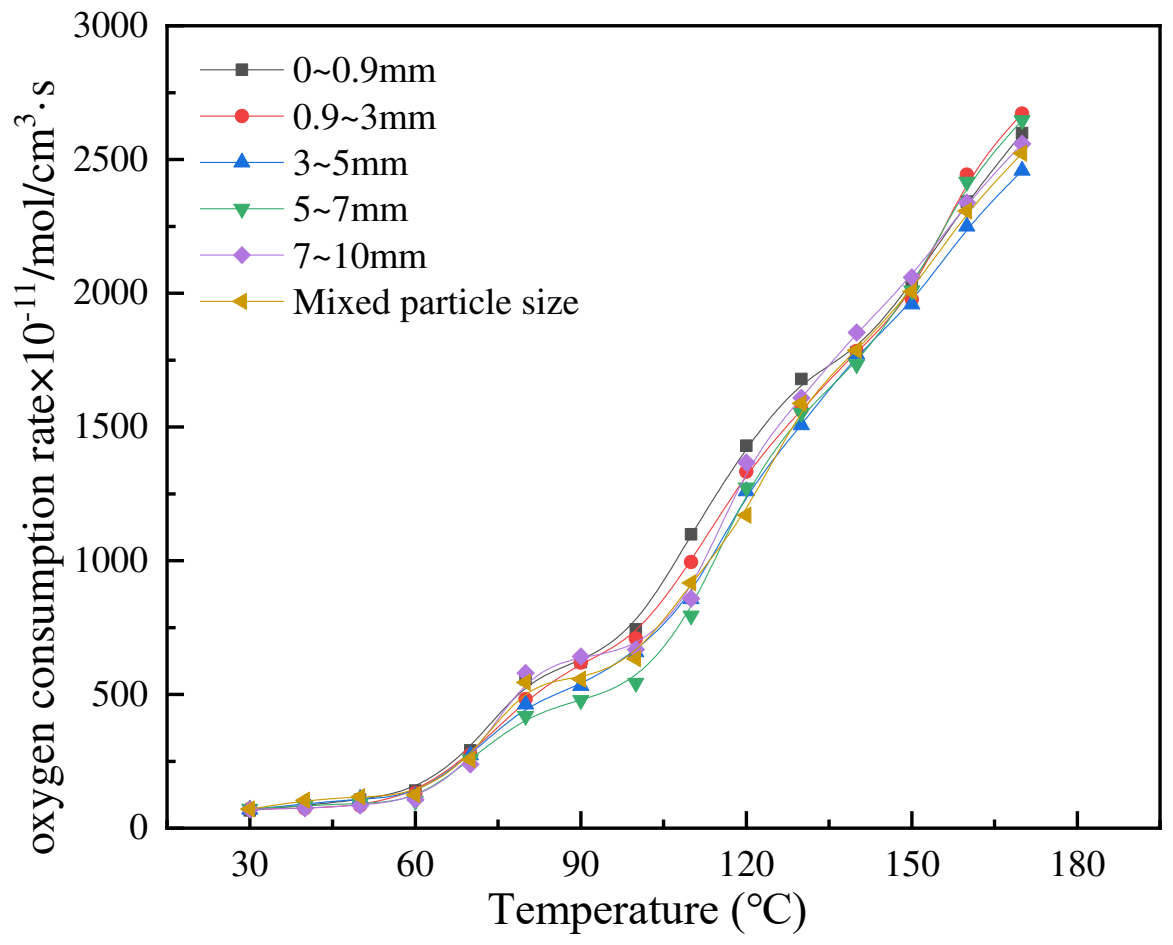

Fig. 2 Curve of the oxygen consumption rate with temperature

140 It can be observed from Fig. 2 that the oxygen consumption rates of coal samples are

141 positively correlated with temperature. As the coal temperature reaches $60^{\circ} \mathrm{C}$, the curve

142 has an inflection point, and the slope of the curve increases. Further, as the coal

143 temperature exceeds $80^{\circ} \mathrm{C}$, the inclination of the curve becomes gentle. Around $100^{\circ} \mathrm{C}$,

144 the curve appears at the inflection point. After $110^{\circ} \mathrm{C}$, there is no inflection point on the 
curve. Fig. 3 shows the curve of the growth rate of oxygen consumption rate with temperature for the different coal samples.

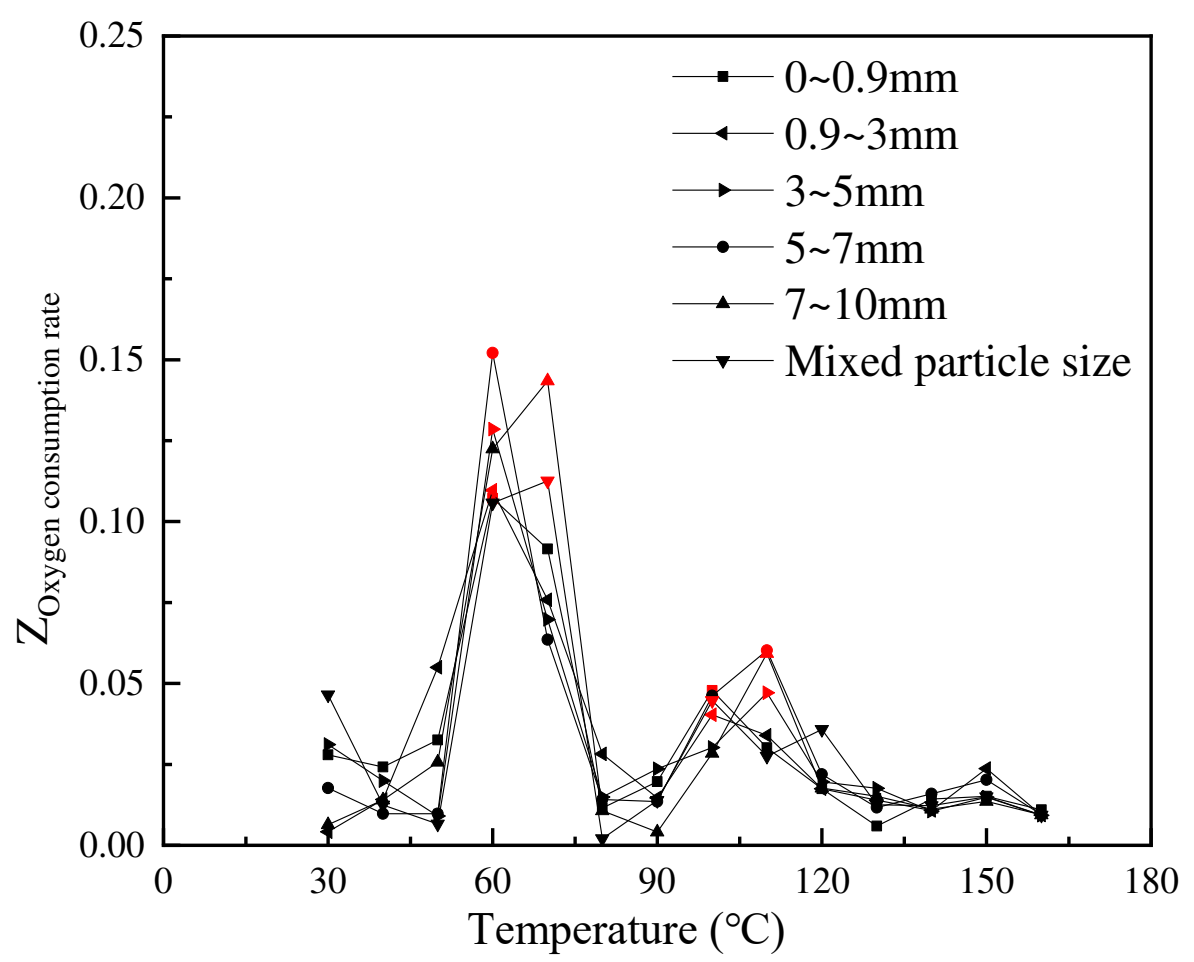

Fig. 3 The growth rate of oxygen consumption rate with temperature

Fig. 3 indicates that change rules of the growth rate of oxygen consumption rate with temperature for all coal samples are similar. At $60^{\circ} \mathrm{C} \sim 70^{\circ} \mathrm{C}$, the first maximum value appears, followed by the second one at $100^{\circ} \mathrm{C} \sim 110^{\circ} \mathrm{C}$. It indicates that the oxygen consumption rate elevates rapidly in these temperature ranges. So, $60^{\circ} \mathrm{C} \sim 70^{\circ} \mathrm{C}$ could be determined to be the critical temperature range for the coal sample, whereas $100^{\circ} \mathrm{C} \sim 110^{\circ} \mathrm{C}$ is identified as the dry cracking temperature range.

\subsection{Single index gas}

\subsubsection{CO}

Fig. 4 shows the variation of $\mathrm{CO}$ concentration with temperature for the coal samples.

It can be observed that $\mathrm{CO}$ gas is detected at the initial temperature $\left(30^{\circ} \mathrm{C}\right)$ for each coal 

influence of particle size on CO production account for its inapplicability for index gas.

161

162

163

164

165

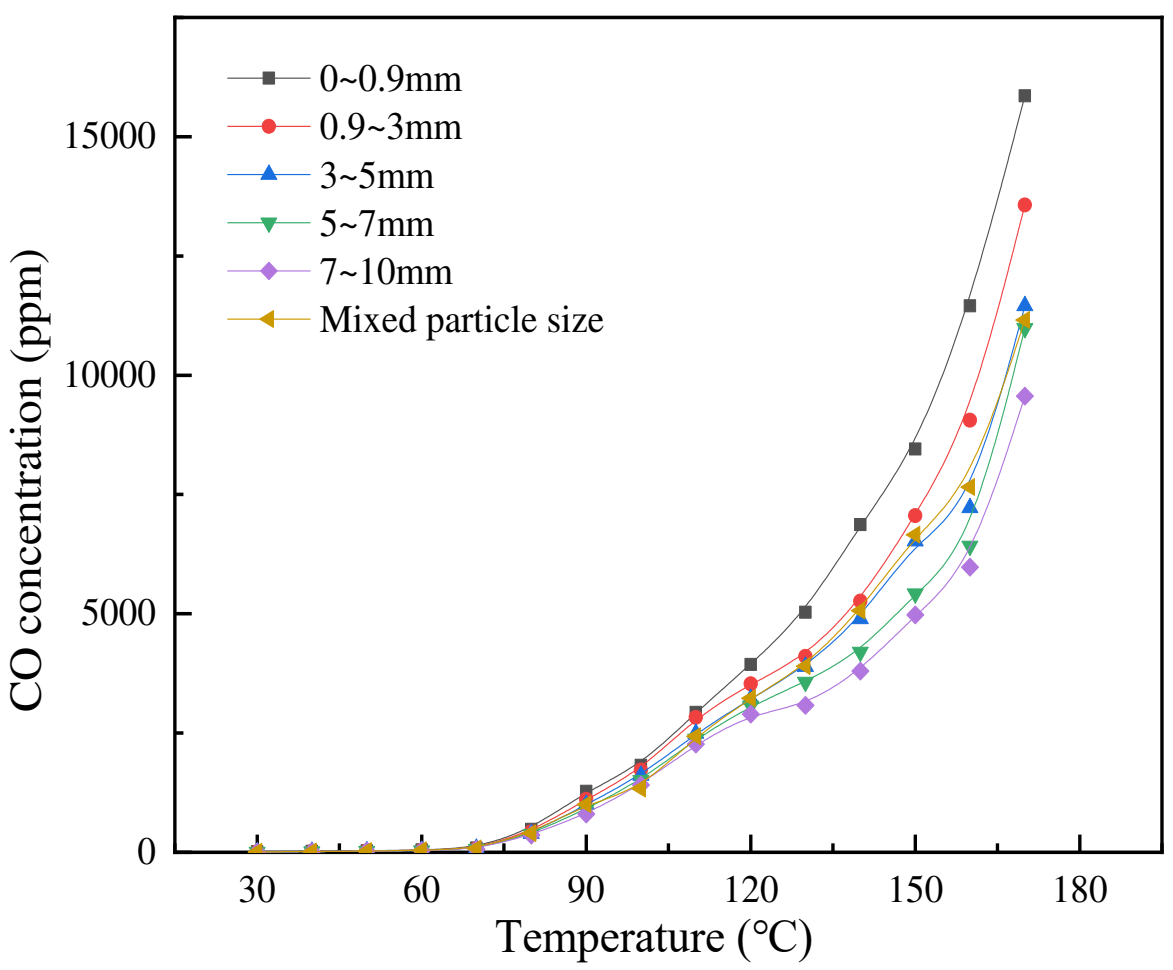

Fig. 4 The variation of $\mathrm{CO}$ concentration with temperature

3.2.2 $\mathrm{C}_{2} \mathrm{H}_{4}$ and $\mathrm{C}_{2} \mathrm{H}_{6}$

Fig. 5 and 6 show the variation of $\mathrm{C}_{2} \mathrm{H}_{4}$ and $\mathrm{C}_{2} \mathrm{H}_{6}$ concentrations with temperature for the coal samples. 


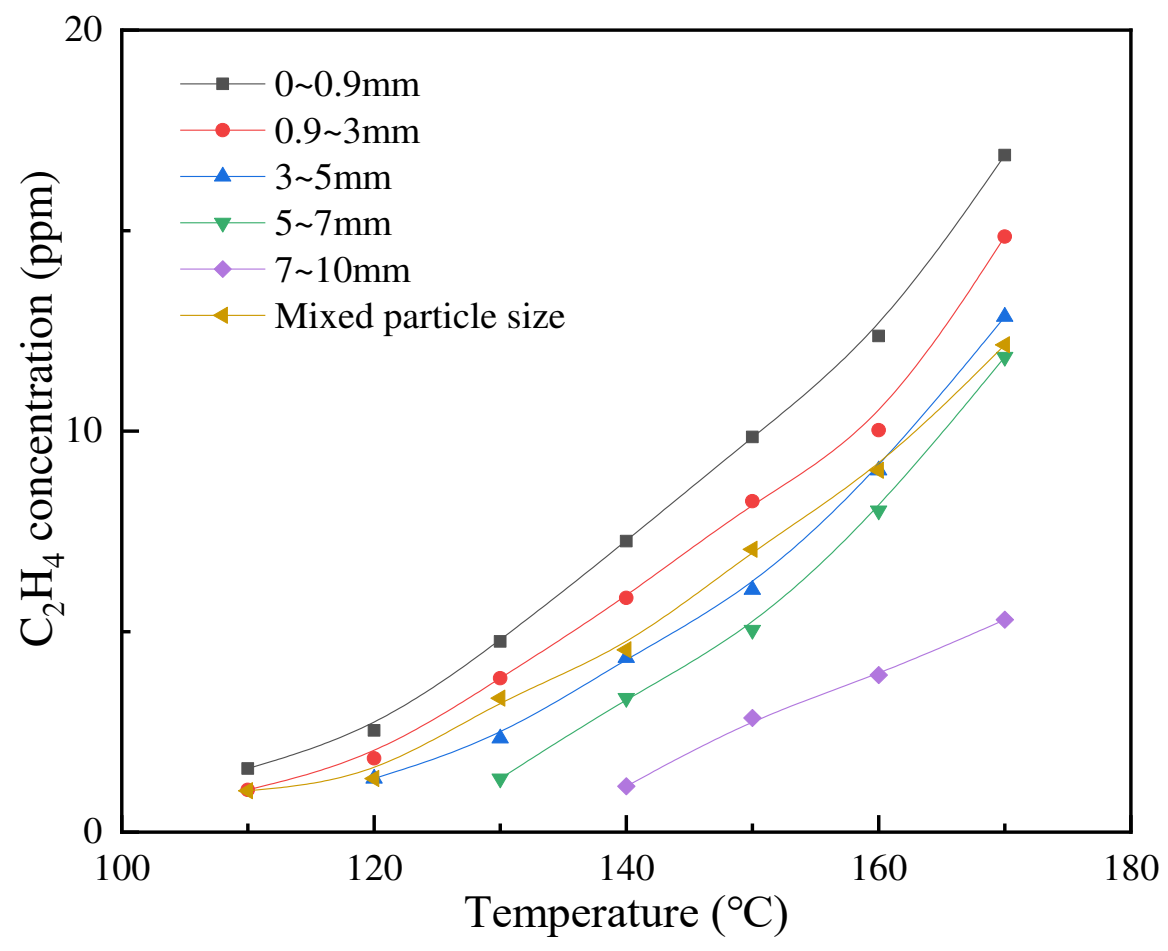

Fig. 5 Curve of the variation of $\mathrm{C}_{2} \mathrm{H}_{4}$ with temperature

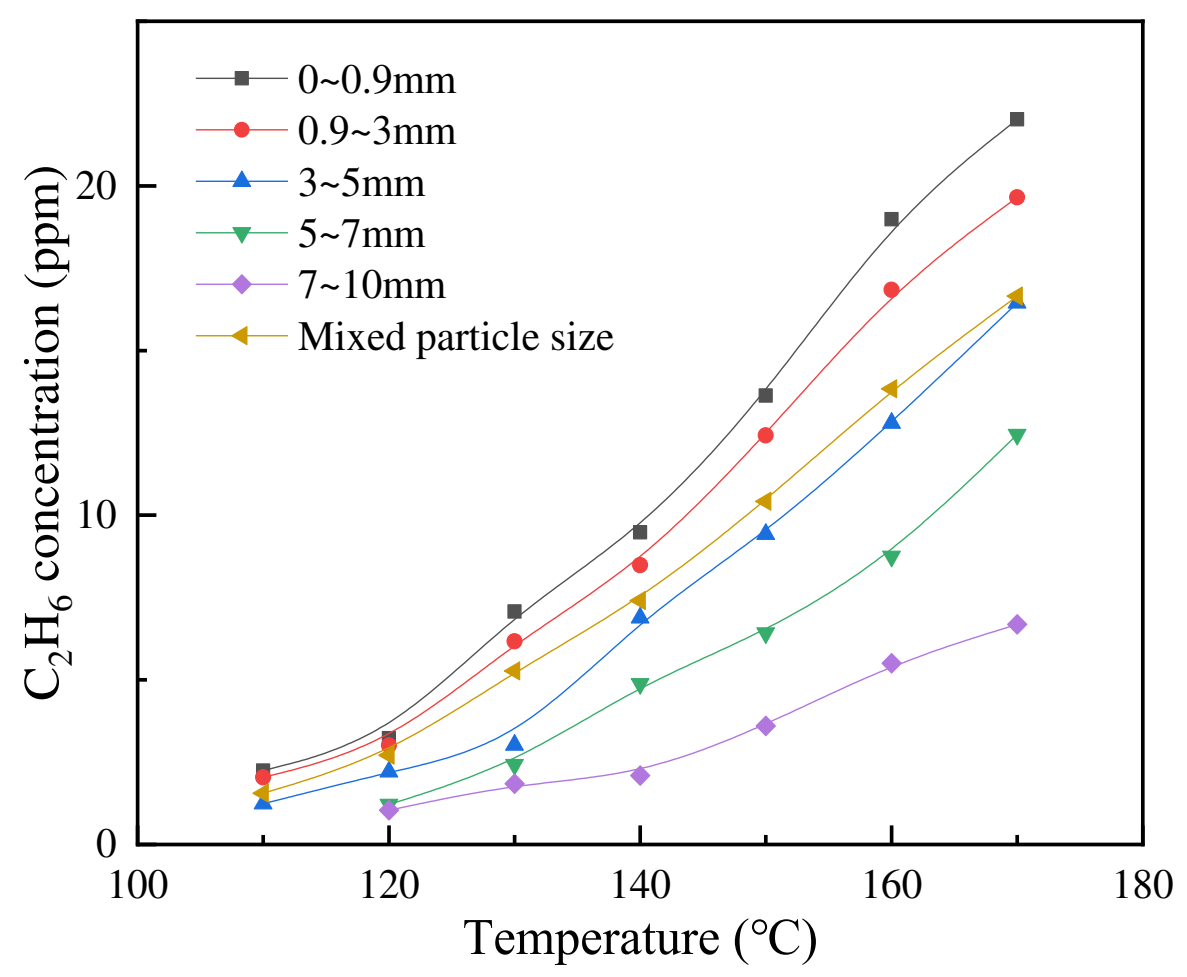

Fig. 6 Curve of the variation of $\mathrm{C}_{2} \mathrm{H}_{6}$ with temperature

170 They indicate that the increasing concentration of $\mathrm{C}_{2} \mathrm{H}_{4}$ and $\mathrm{C}_{2} \mathrm{H}_{6}$ with temperature are associated with coal particle size. At the same temperature, the smaller particle size coal 
sample could generate more $\mathrm{C}_{2} \mathrm{H}_{4}$ and $\mathrm{C}_{2} \mathrm{H}_{6}$ gases. Both gases can be detected as the temperature reaches above $110^{\circ} \mathrm{C}$. The generation of $\mathrm{C}_{2} \mathrm{H}_{6}$ and $\mathrm{C}_{2} \mathrm{H}_{4}$ gases is related to the high-temperature cracking of coal. Therefore, the appearance of $\mathrm{C}_{2} \mathrm{H}_{4}$ and $\mathrm{C}_{2} \mathrm{H}_{6}$ can be used as the index gas to determine the dry cracking temperature.

\subsection{Composite index}

Due to the complex environment, such as airflow under coal mines, the air would affect the single index gas concentration. It is difficult to precisely judge the degree of coal spontaneous combustion by single gas concentration, while the composite index involving the ratio of at least two gas concentrations can reduce the influence of the environment on the indexes (Liang et al. 2019).

\subsection{1 $\mathrm{CO}_{2} / \mathrm{CO}$}

Fig. 7 shows the variation of $\mathrm{CO}_{2} / \mathrm{CO}$ of all coal samples with temperature.

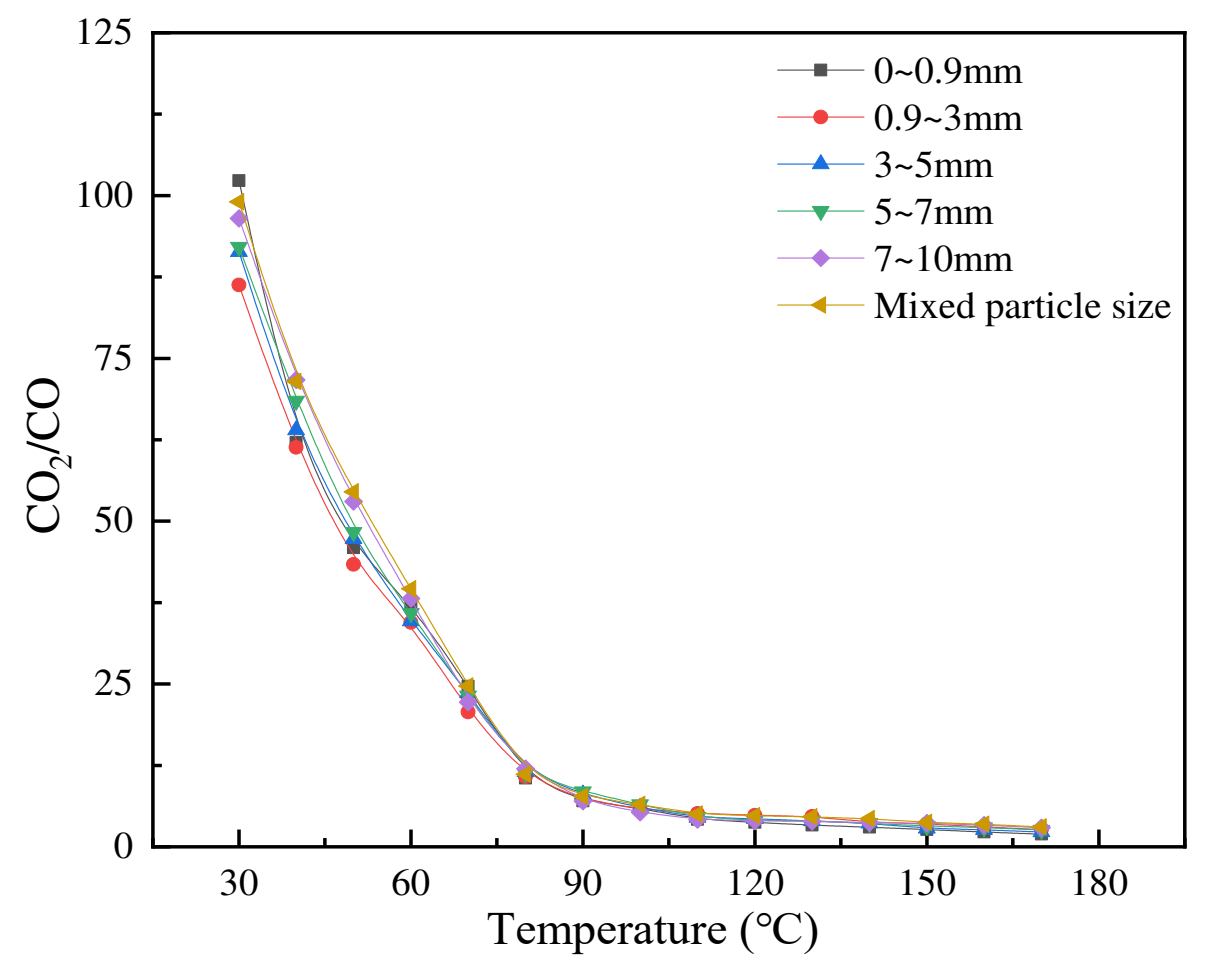

Fig. 7 The variation of $\mathrm{CO}_{2} / \mathrm{CO}$ with temperature 
Fig. 7 indicates that there is a negative correlation between the $\mathrm{CO}_{2} / \mathrm{CO}$ value and temperature. It exhibits a certain degree of dispersion before $80^{\circ} \mathrm{C}$ and the curve fluctuation after $80^{\circ} \mathrm{C}$ is not intuitively shown in the figure. Therefore, it is necessary to further study whether the influence of coal particle size on the variation of $\mathrm{CO}_{2} / \mathrm{CO}$ with temperature is within an acceptable range.

\section{$3.3 .2 \mathrm{O}_{2} /\left(\mathrm{CO}+\mathrm{CO}_{2}\right)$}

Fig. 8 shows the variation of $\mathrm{O}_{2} /\left(\mathrm{CO}+\mathrm{CO}_{2}\right)$ of all coal samples with temperature.

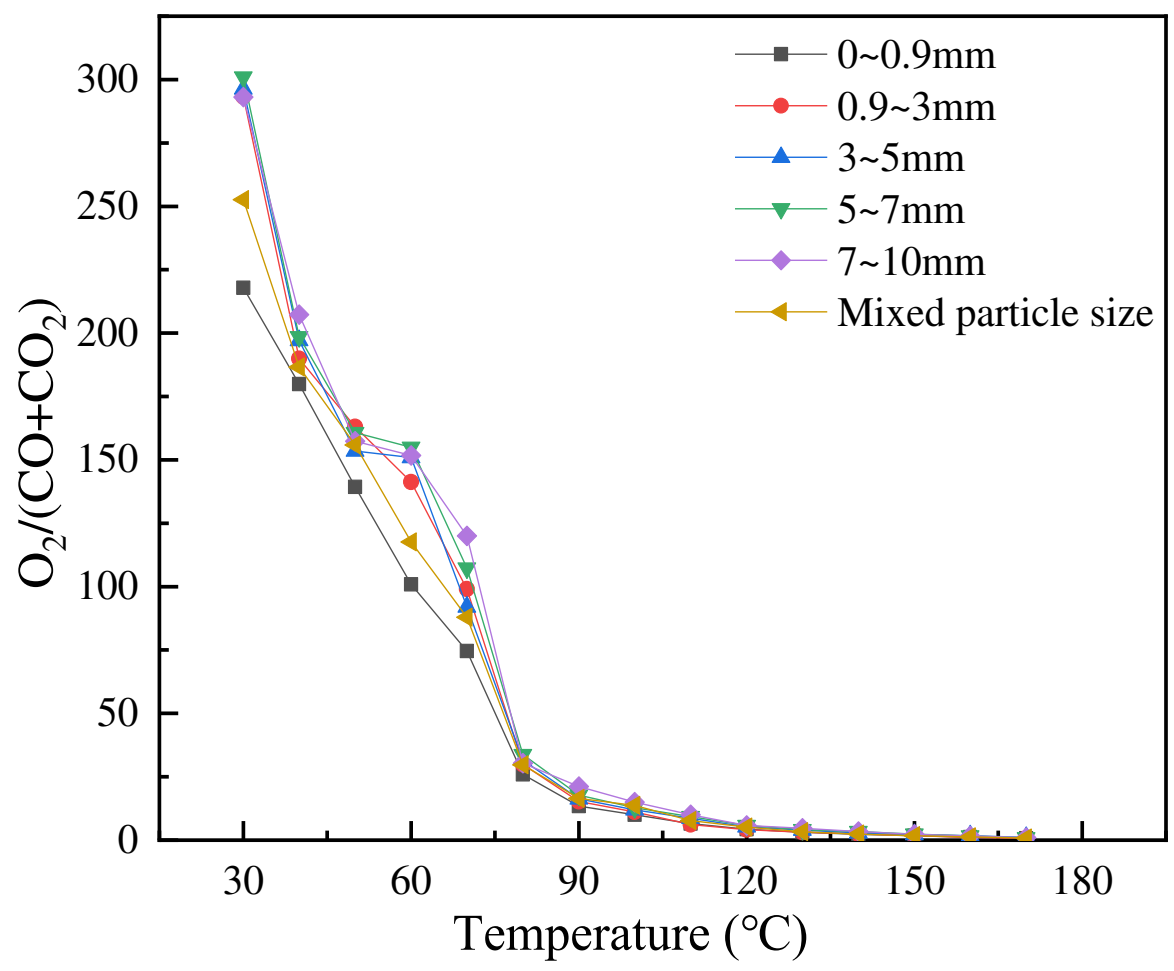

Fig. 8 The variation of $\mathrm{O}_{2} /\left(\mathrm{CO}+\mathrm{CO}_{2}\right)$ with temperature

The value of $\mathrm{O}_{2} /\left(\mathrm{CO}+\mathrm{CO}_{2}\right)$ decreases as the temperature rises. At $80^{\circ} \mathrm{C}$, the curve approaches the inflection point, and the inclination decreases rapidly. At this stage, the coal temperature reaches the critical temperature, and the coal-oxygen reaction takes place speedily. Consequently, an increment of the oxygen consumption rate as well as the rate of production of $\mathrm{CO}$ and $\mathrm{CO}_{2}$ leads to a decrease of the $\mathrm{O}_{2}$ content and an increase of the $\mathrm{CO}$ 
and $\mathrm{CO}_{2}$ contents, and a decreased amplitude of $\mathrm{O}_{2} /\left(\mathrm{CO}+\mathrm{CO}_{2}\right)$ value increases accordingly.

201 As the coal temperature exceeds $80^{\circ} \mathrm{C}$, the fluctuations are difficult to be judged directly

202 from the curve, thus, it is necessary to further study the influence of coal particle size on

203 the variation of $\mathrm{O}_{2} /\left(\mathrm{CO}+\mathrm{CO}_{2}\right)$ with temperature.

Fig. 9 shows the variation of $\mathrm{O}_{2} / \mathrm{CH}_{4}$ of all coal samples with temperature.

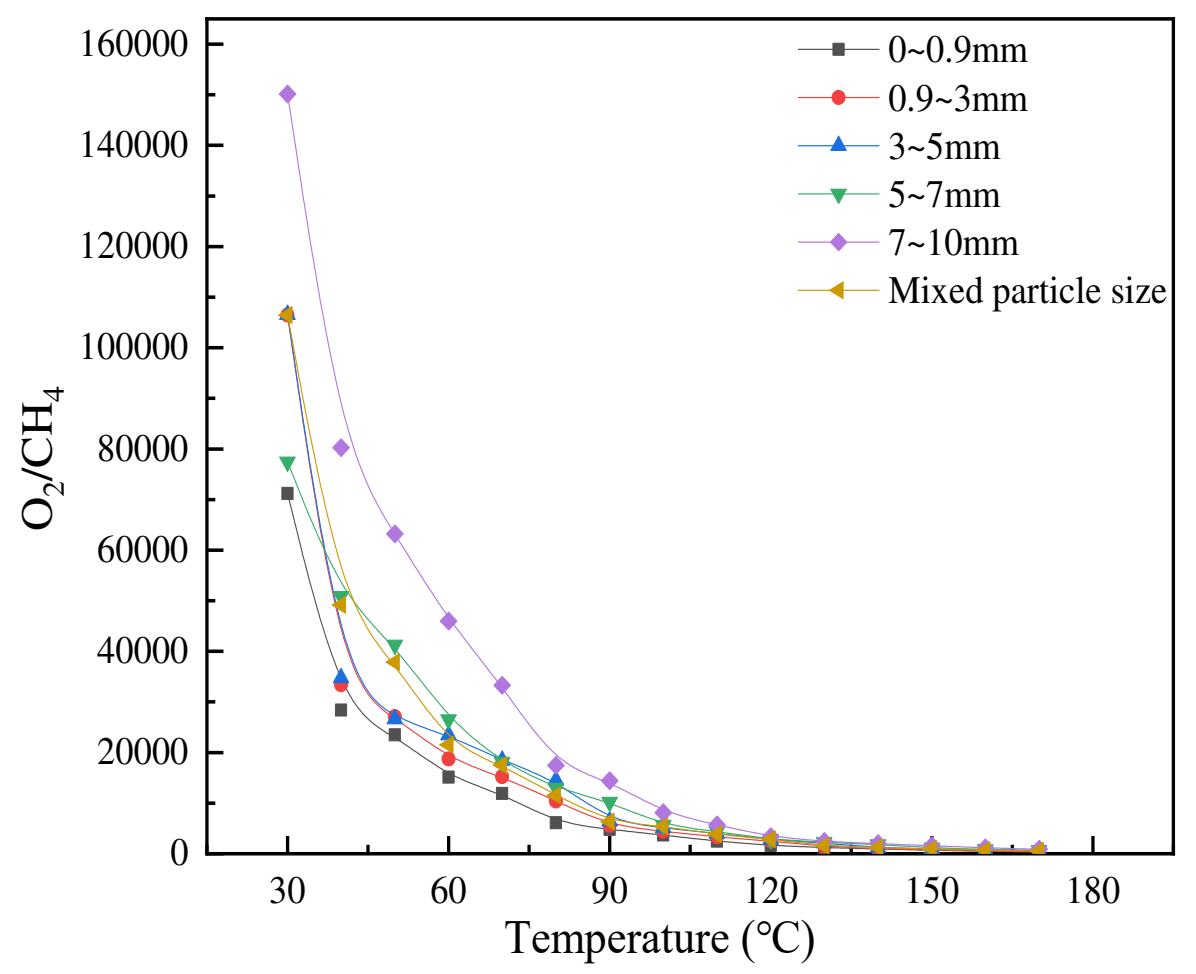

Fig. 9 Curve of the variation of $\mathrm{O}_{2} / \mathrm{CH}_{4}$ with temperature

As observed from Fig. 9, the $\mathrm{O}_{2} / \mathrm{CH}_{4}$ value is negatively correlated with the temperature.

Below $90^{\circ} \mathrm{C}$, the coal particle size have a certain influence on the $\mathrm{O}_{2} / \mathrm{CH}_{4}$ value, and as the temperature exceeds $90^{\circ} \mathrm{C}$, the fluctuations in the curves are not clear.

212 Fig. 10 shows the variation of $\mathrm{CO} / \mathrm{CH}_{4}$ with temperature. 


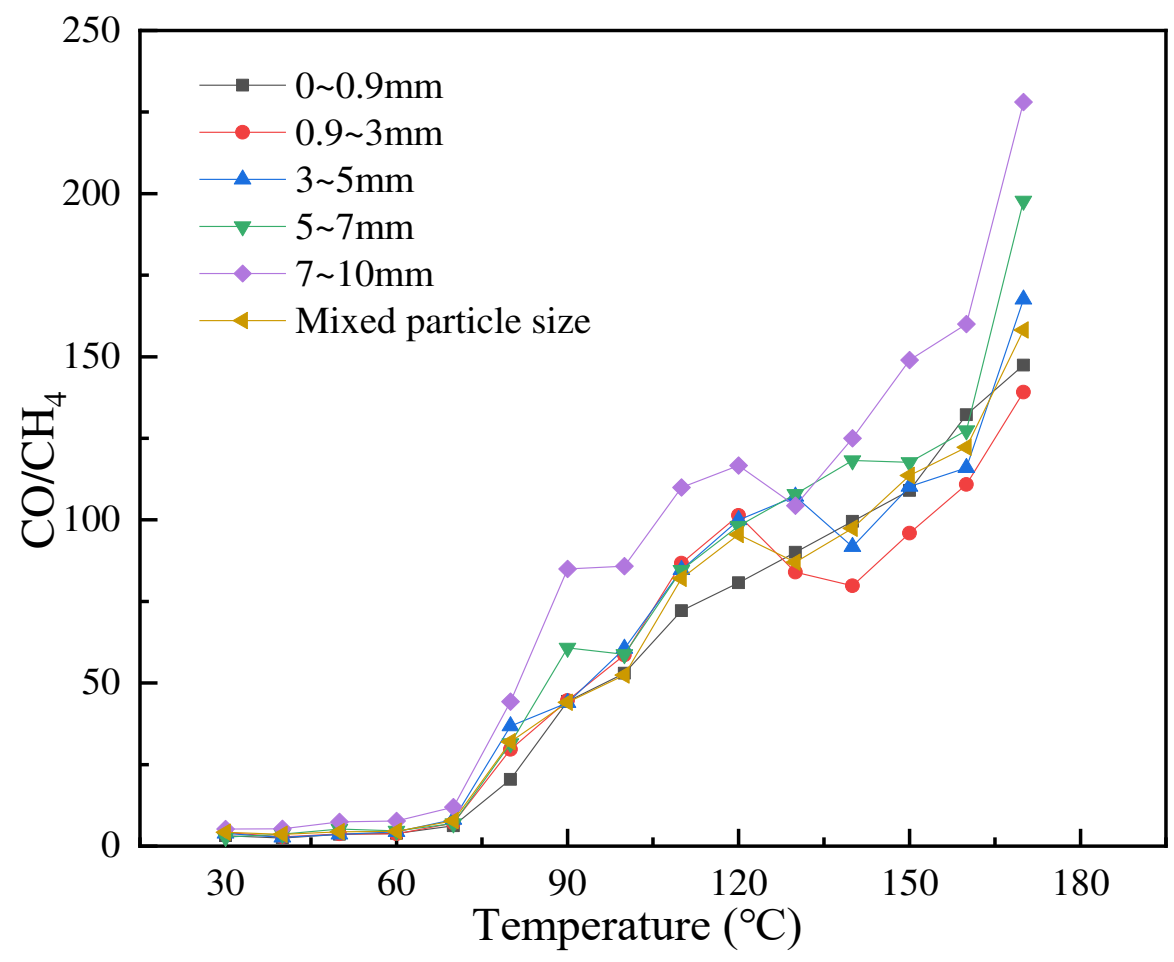

Fig. 10 The variation of $\mathrm{CO} / \mathrm{CH}_{4}$ with temperature

215 Fig. 10 illustrates that the $\mathrm{CO} / \mathrm{CH}_{4}$ value gradually increases with the increasing

216 temperature. The values of all coal samples exhibit a certain degree of dispersion, when

217 the coal temperature reaches in the range of $120^{\circ} \mathrm{C} \sim 140^{\circ} \mathrm{C}$. Thus, the coal particle size

218 influences the variation of $\mathrm{CO} / \mathrm{CH}_{4}$ with temperature.

$219 \quad 3.3 .5 \mathrm{O}_{2} / \mathrm{CO}$

220 Fig. 11 shows the variation of $\mathrm{O}_{2} / \mathrm{CO}$ of all coal samples with temperature. 


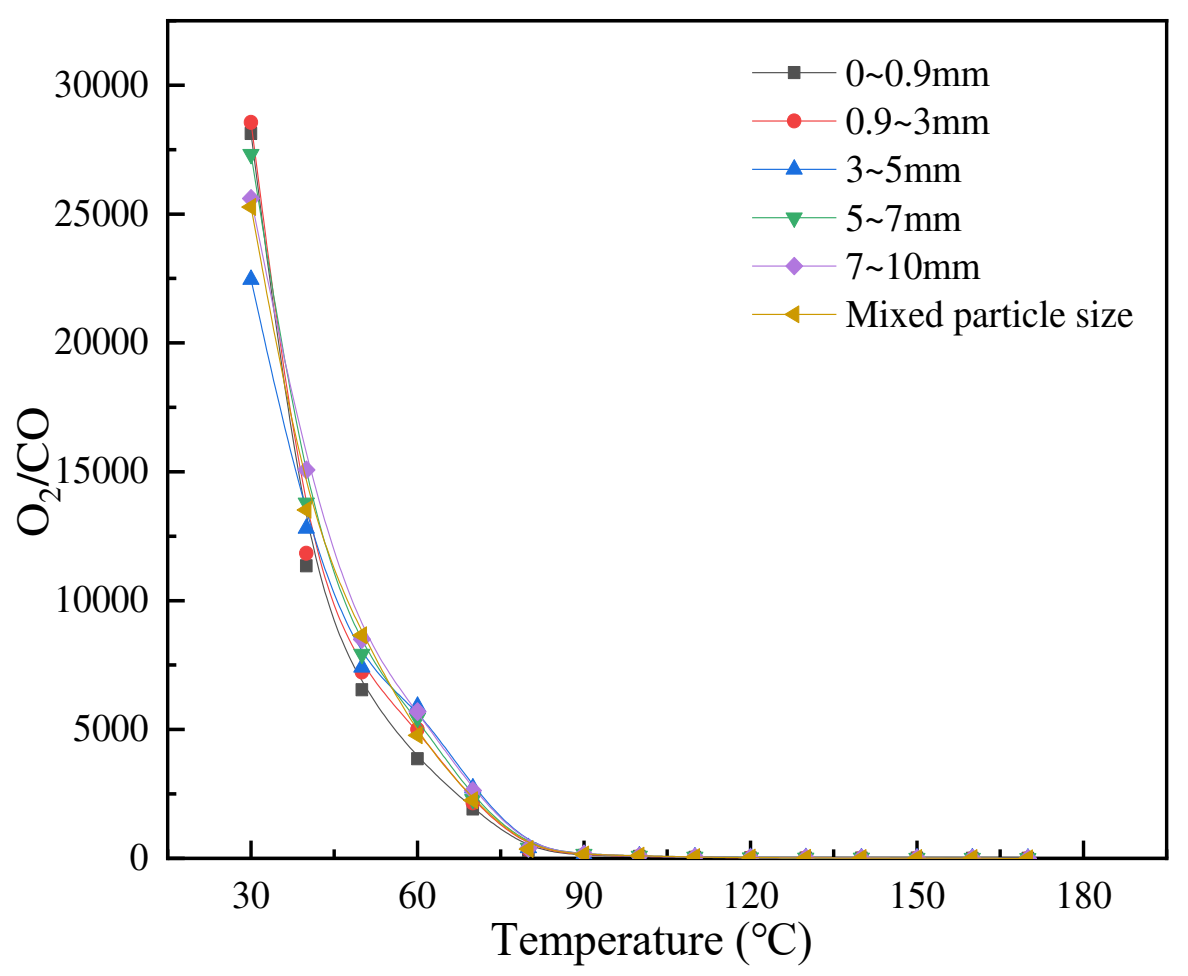
Fig. 11 The variation of $\mathrm{O}_{2} / \mathrm{CO}$ with temperature

223 Fig. 11 indicates that there is a negative correlation between the $\mathrm{O}_{2} / \mathrm{CO}$ value and coal 224 temperature for all samples. Before $80^{\circ} \mathrm{C}$, the differences among the index values of each 225 coal sample were various, and it is difficult to observe directly from the figure after $80^{\circ} \mathrm{C}$.

$226 \quad 3.3 .6 \mathrm{CO}_{2} / \mathrm{O}_{2}$

227 Fig. 12 shows the variation of $\mathrm{CO}_{2} / \mathrm{O}_{2}$ of all samples with temperature. 


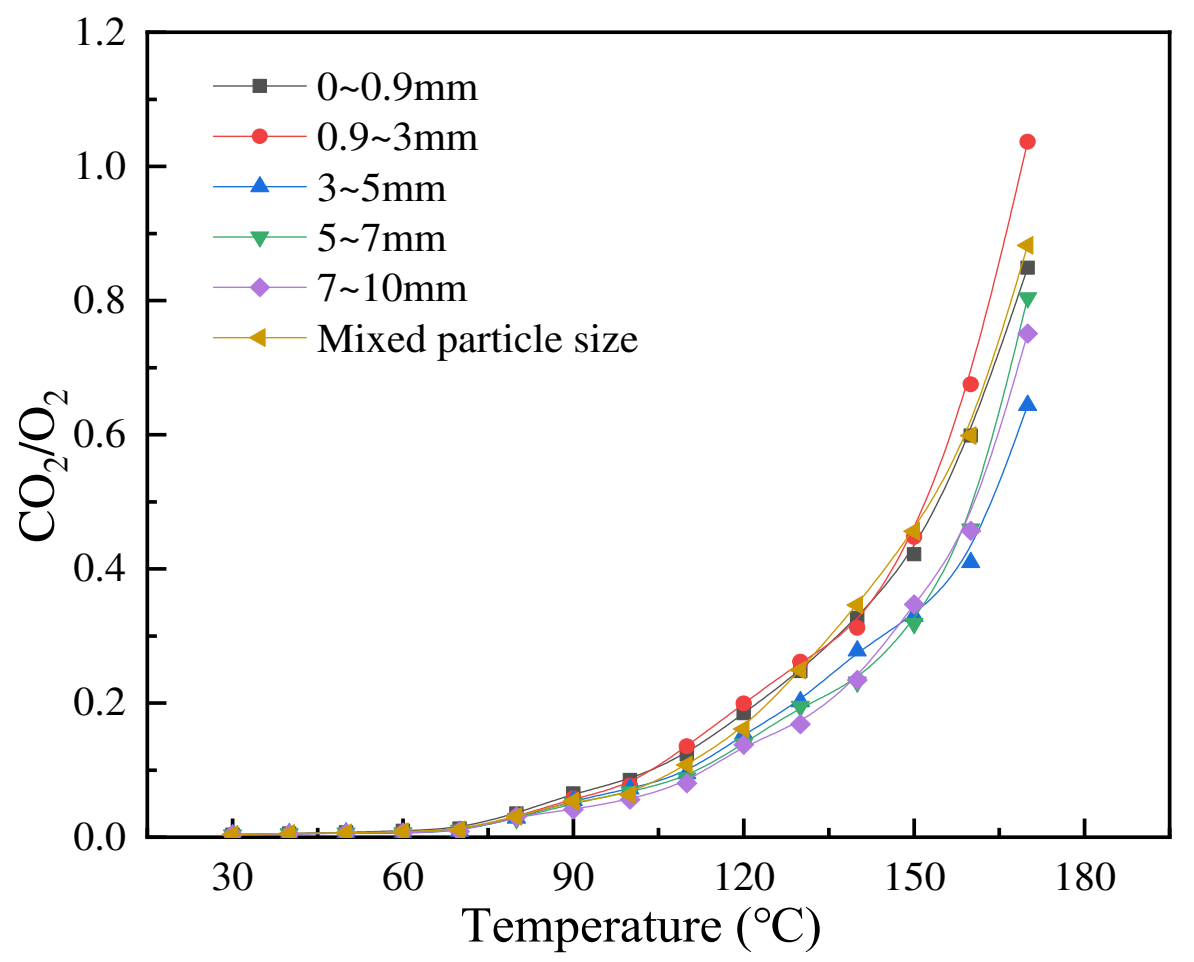

Fig. 12 The variation of $\mathrm{CO}_{2} / \mathrm{O}_{2}$ with temperature

230 Fig. 12 shows that there is a positive correlation between the $\mathrm{CO}_{2} / \mathrm{O}_{2}$ value and coal 231 temperature. The particle size of coal influences the variation of $\mathrm{CO}_{2} / \mathrm{O}_{2}$ with temperature.

232 But, whether the degree of influence is acceptable requires further study.

\subsection{Evaluation of forecast indexes for spontaneous combustion}

234 To ascertain the reliability of the different spontaneous combustion indexes numerically, the coefficient of variation and grey relational analysis were used to evaluate the quantitative spontaneous combustion indexes. Combining with the two characteristic temperatures, three stages could be divided for the classification of coal spontaneous

238 combustion.

\subsubsection{Coefficient of Variation Analysis}

240 The coefficient of variation $\left(C_{v}\right)$ is a standardized measure of the dispersion degree for the probability distribution. It reflects the degree of difference in the size of a set of data. The 
$C_{v}$ of more than $30 \%$ usually indicates that this set of data has a large difference and a high degree of dispersion (Brown and Charles 1998; He and Oyadiji 2001). By the $C_{v}$ of the

244 coal spontaneous combustion indexes at the different coal particle sizes, the influence level

245 can be obtained. A smaller $C_{v}$ indicates a lower impact of particle size on the coal 246 spontaneous combustion index. The calculate method of coefficient of variation is as Eq. 247 (4):

$$
C_{v}=\frac{\sqrt{\frac{1}{n-1} \sum_{i=1}^{n}\left(X_{i}-\bar{X}\right)^{2}}}{\bar{X}}
$$

249 Where $C_{v}$ is the coefficient of variation, $n$ is the number of particle size, $X_{i}$ is the index 250 value of spontaneous combustion of all coal samples at the same temperature, and $\bar{X}$ is the 251 average value of $X_{i}$.

252 Figs. 13(a) and (b) show the $C_{v}$ of coal spontaneous combustion indexes with coal 253 temperature. Fig. 14 shows the average $C_{v}$. 


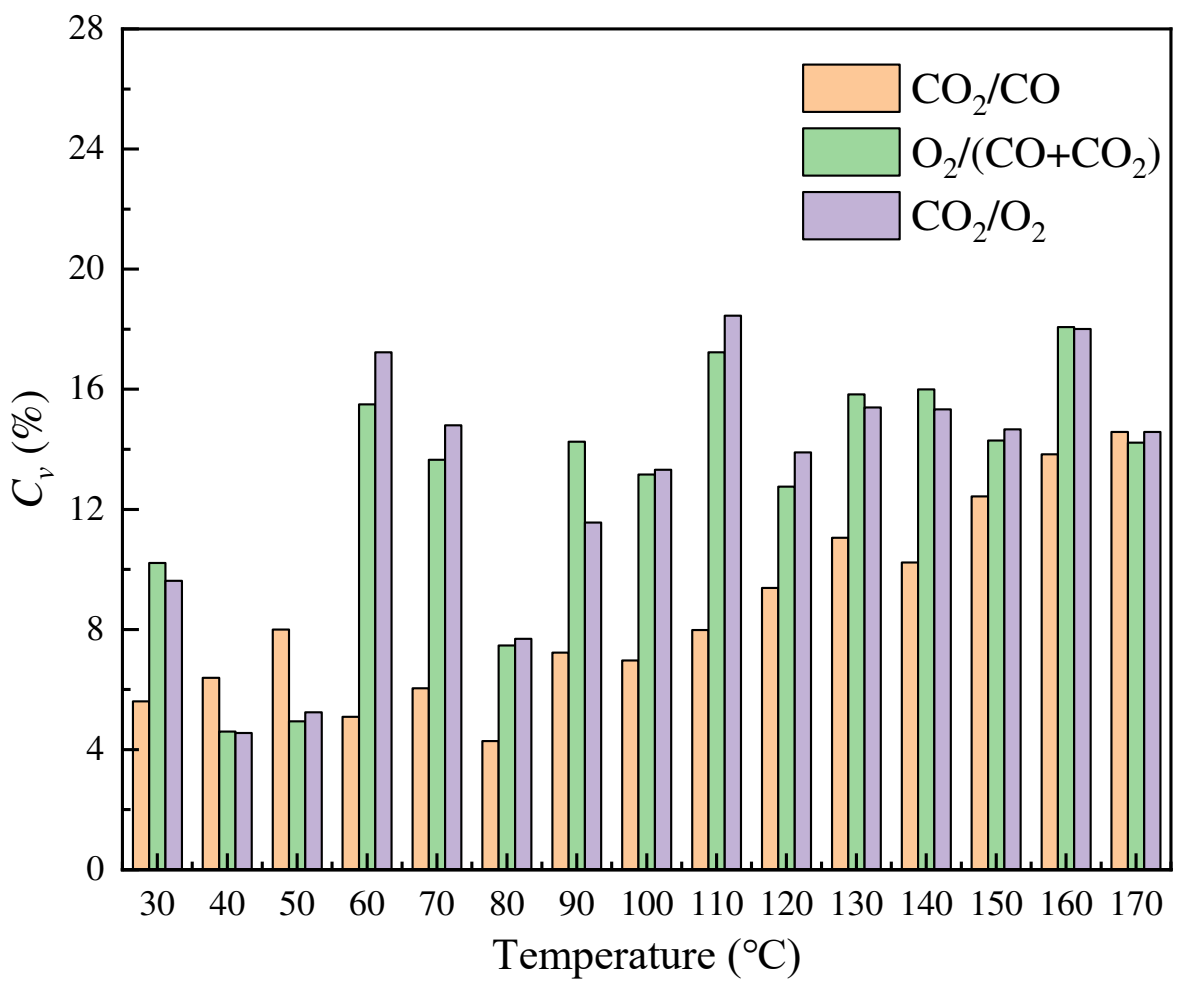

(a)

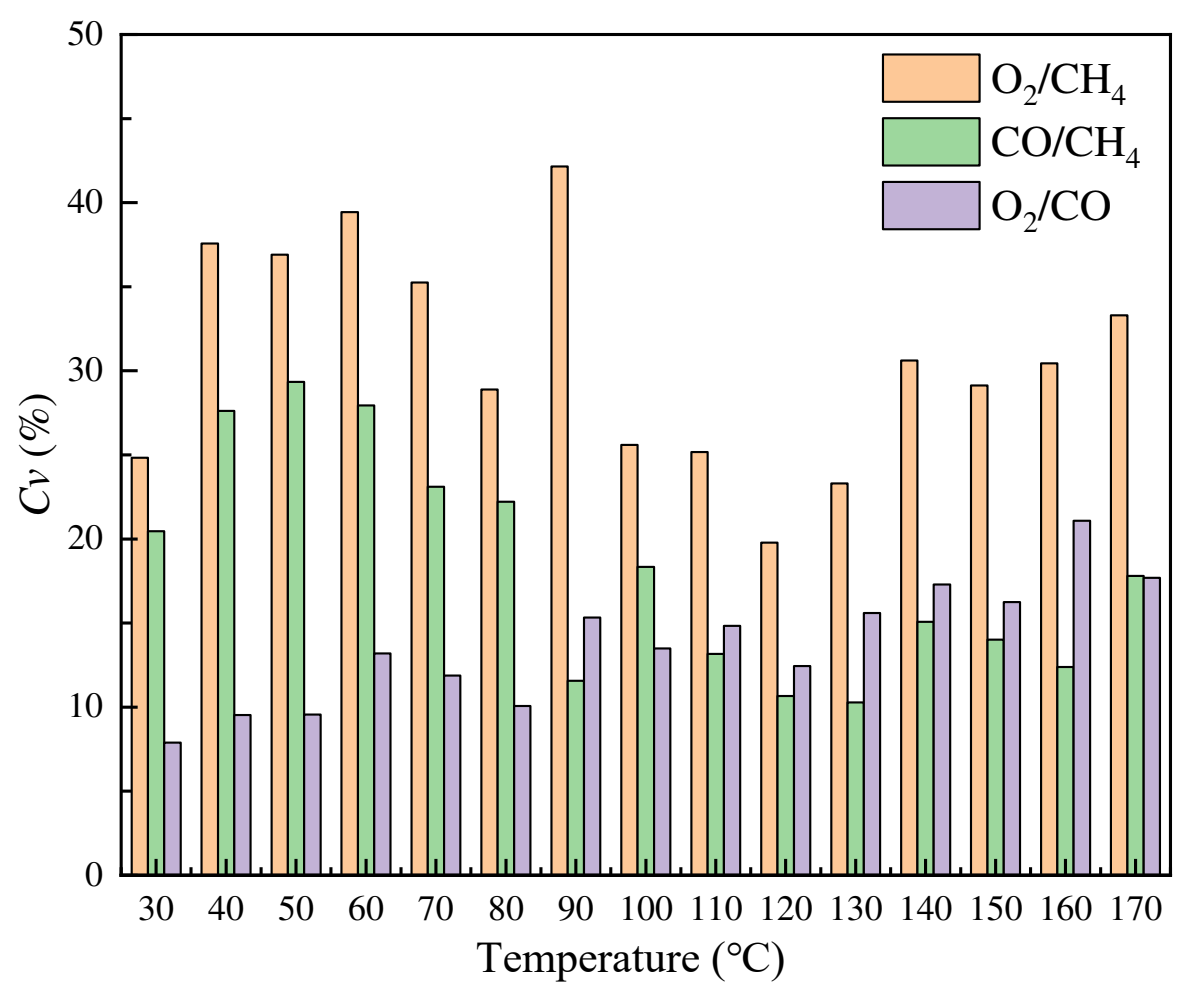

(b)

Fig. 13 The $C_{v}$ of indexes with coal temperature 


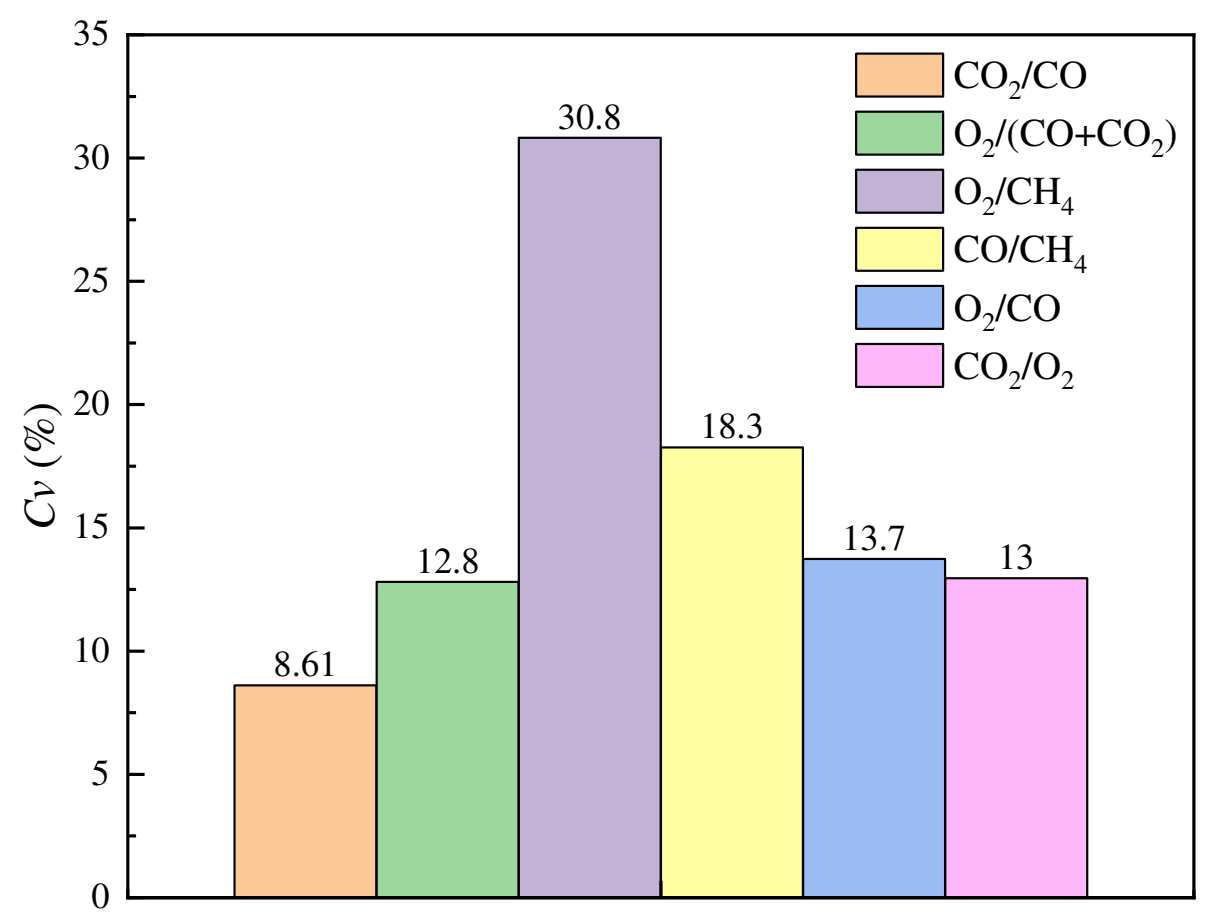

Fig. 14 The average $C_{v}$ of coal spontaneous combustion indexes

Fig. 13 illustrates that the $C_{v}$ values of $\mathrm{CO}_{2} / \mathrm{CO} 、 \mathrm{O}_{2} /\left(\mathrm{CO}+\mathrm{CO}_{2}\right) 、 \mathrm{O}_{2} / \mathrm{CO}$ and $\mathrm{CO}_{2} / \mathrm{O}_{2}$ at overwhelming majority temperature are less than $20 \%$. Only a small fraction exceeds $20 \%$. Half of the $C_{v}$ value of $\mathrm{CO} / \mathrm{CH}_{4}$ is below $20 \%$. The $C_{v}$ value of $\mathrm{O}_{2} / \mathrm{CH}_{4}$ at each temperature point is higher than $20 \%$, further, the $C_{v}$ value at a few temperature points is above $30 \%$. Subsequently, Fig. 14 illustrates that the average $C_{v}$ value for each spontaneous combustion index was determined. Among them, $C_{v}$ value of $\mathrm{O}_{2} / \mathrm{CH}_{4}$ is the highest and exceeds $30 \%$, indicating that the dispersion degree of values of $\mathrm{O}_{2} / \mathrm{CH}_{4}$ of each coal sample is the highest, and the coal particle size has a greater influence on it, other indexes with lower $C_{v}$ values are less influenced by coal particle size.

\subsubsection{Grey relational analysis}

The grey relational coefficient could be used to represent the difference degree of the geometric shapes between the curves (Ren et al. 2020; Zhao et al. 2020). The rate of oxygen consumption can be closely associated with the coal sample temperature. Therefore, a 
reference series reflecting the system characteristics are determined from the rate of oxygen consumption (If the coal spontaneous combustion indexes show a downward trend with the temperature change, the reciprocal of the rate of oxygen consumption is used as a reference series to reflect the characteristics of the system). The coal spontaneous combustion index values form the comparison series (dimensionless) and average (used in this study) value and initial value methods are usually used to generate the reference series. The corresponding equation is as Eq. (5):

$$
\xi_{i}(k)=\frac{\operatorname{minmin}_{i}\left|t(k)-X_{i}(k)\right|+\xi \operatorname{maxmax}_{i}\left|t(k)-X_{i}(k)\right|}{\left|t(k)-X_{i}(k)\right|+\xi \operatorname{maxmax}_{i}\left|t(k)-X_{i}(k)\right|}
$$

Where $\xi_{i}(k)$ is the grey relational coefficient of $X_{i}$ to $t$ at time $\mathrm{k}, \xi$ is the resolution coefficient (generally between 0 and $1,0.5$ in this study), where $\operatorname{minmin}_{i}\left|t(k)-X_{i}(k)\right|$ and $\max _{i} \max _{k}\left|t(k)-X_{i}(k)\right|$ are the two-level minimum and two-level maximum respectively.

The grey relational coefficient $\gamma_{i}$ represents the mean value of $\xi_{i}(k)$. Fig. 15 shows the grey relational coefficient of each coal spontaneous combustion index. Among them, except for $\mathrm{CO} / \mathrm{CH}_{4}$, the grey correlation coefficients of the other indexes are higher than 0.75 , which are at a relatively high level. The grey correlation coefficient of $\mathrm{CO} / \mathrm{CH}_{4}$ is 0.66 , which is at a low level. 


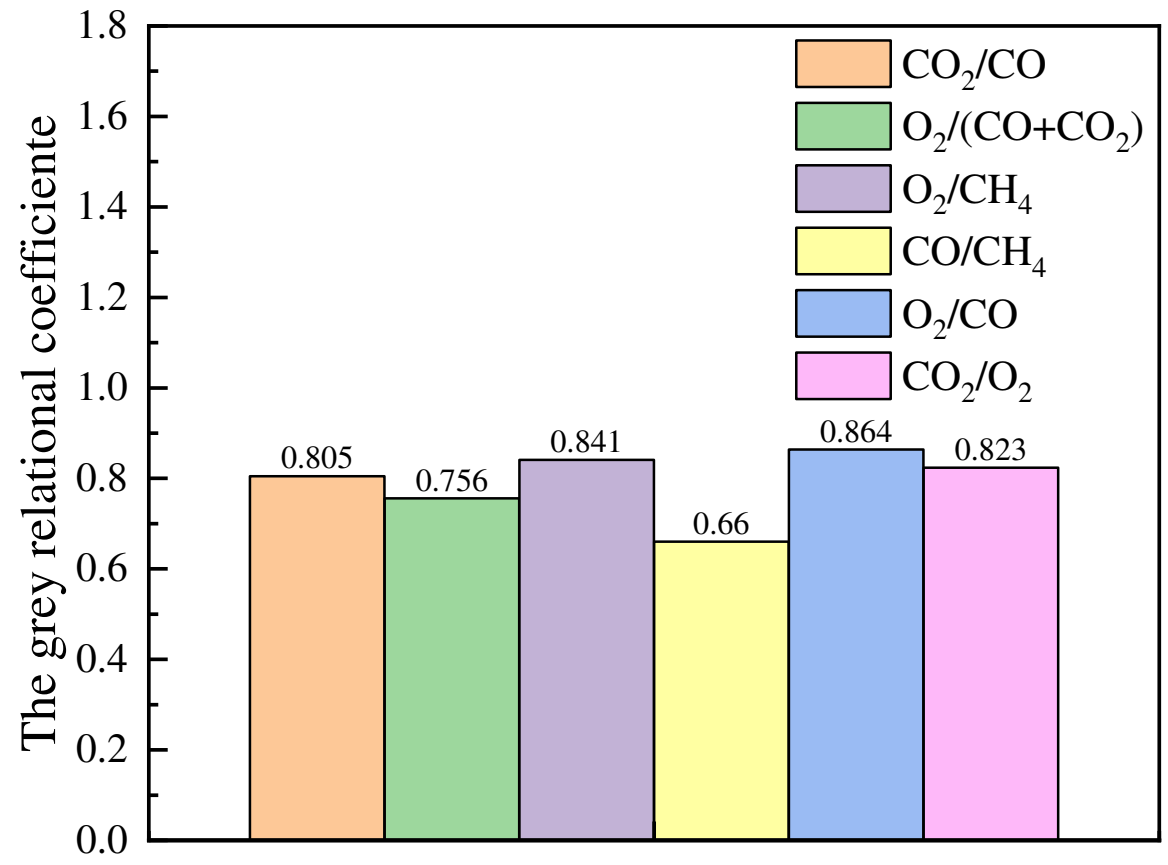

291 Fig. 15 The grey relational coefficient of different coal spontaneous combustion indexes

\subsubsection{Optimization analysis of weighted grey relation}

The influence of particle size on the variation of coal spontaneous combustion indexes with temperature cannot be ignored. In this study, the weighted grey relational analysis is used to optimize the selection of the coal spontaneous combustion index, which can make the selection of prediction and forecast index of coal spontaneous combustion more precise and reliable. The weighted of the $C_{v}$ is as Eq. (6):

$$
w_{i}=\frac{1}{C_{V}}
$$

Where $w_{i}$ is the weighted coefficient of variation.

The equation for the weighted grey relational degree can be given as Eq. (7):

$$
R_{i}=\frac{1}{n} \sum_{i=1}^{n} \xi_{i}(K) \cdot w_{i}
$$

Fig. 16 shows the weighted grey relational degree of various indexes and their ranking results. It can be seen that $R_{\mathrm{CO} 2 / \mathrm{CO}}$ is the highest, followed by $R_{\mathrm{CO} / \mathrm{O} 2}$ and $R_{\mathrm{O} 2 /(\mathrm{CO}+\mathrm{CO} 2) \text {, and }}$ 
$R_{C O / C H 4}$ and $R_{O 2 / C H 4}$ are at a lower level, indicating that the reliability of $\mathrm{CO}_{2} / \mathrm{CO}$ is the

highest as a coal spontaneous combustion index. As the limit value, the median $R_{\text {median }}$ was used to select the indexes. When the weighted grey relational degree is higher than the $R_{\text {median }}$, it could be the prediction and forecast index of coal spontaneous combustion.

$\mathrm{O}_{2} /\left(\mathrm{CO}+\mathrm{CO}_{2}\right)$ as the auxiliary index.

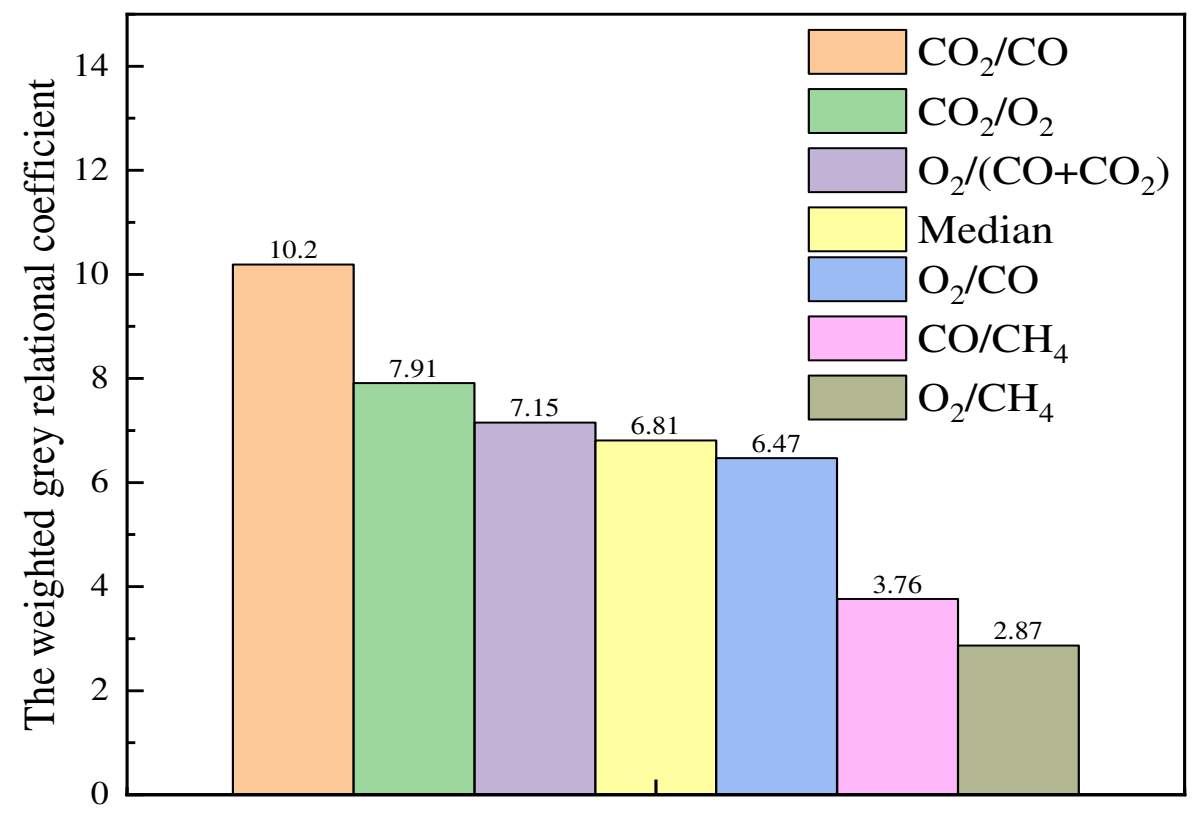

Fig. 16 The weighted grey relational degree of each coal spontaneous combustion indexes

312 The grading forecasting index system of coal spontaneous combustion is shown in Table 1.

313 Table 1 Grading forecasting index system of coal spontaneous combustion

\begin{tabular}{cccccc}
\hline Index type & First index & \multicolumn{2}{c}{ Second index } & \multicolumn{2}{c}{ Confirmation index } \\
\hline Index content & $\mathrm{CO}_{2} / \mathrm{CO}$ & $\mathrm{CO}_{2} / \mathrm{O}_{2}$ & $\mathrm{O}_{2} /\left(\mathrm{CO}+\mathrm{CO}_{2}\right)$ & $\mathrm{C}_{2} \mathrm{H}_{4}$ & $\mathrm{C}_{2} \mathrm{H}_{6}$ \\
Critical temperature & $20.68 \sim 39.62$ & $0.006 \sim 0.013$ & $74.54 \sim 154.92$ & & \\
$\quad / 60 \sim 70^{\circ} \mathrm{C}$ & & & & & \\
$\begin{array}{c}\text { Dry cracking } \\
\text { temperature }\end{array}$ & $4.18 \sim 6.52$ & $0.056 \sim 0.135$ & $6.18 \sim 15.03$ & appears & appears \\
$/ 100 \sim 110^{\circ} \mathrm{C}$ & & & & & \\
\hline
\end{tabular}




\section{Conclusions}

316 In this study, the growth rate analysis method was used to identify characteristic

317 temperatures of the coal spontaneous combustion by temperature-programmed test. the

318 critical temperature range for the coal sample is determined to be $60^{\circ} \mathrm{C} \sim 70^{\circ} \mathrm{C}$, whereas the

319 dry cracking temperature range is $100^{\circ} \mathrm{C} \sim 110^{\circ} \mathrm{C}$. Based on the variation of $\mathrm{CO}, \mathrm{C}_{2} \mathrm{H}_{4}$, and

$320 \mathrm{C}_{2} \mathrm{H}_{6}$ during coal oxidation with consideration of particle sizes, $\mathrm{C}_{2} \mathrm{H}_{4}$ and $\mathrm{C}_{2} \mathrm{H}_{6}$ were

321 selected as the confirmation indexes for the coal temperature to reach the dry cracking

322 temperature.

323 The coefficient of variation was used to analyze the influence of coal particle size on

324 composite indexes, $\mathrm{CO}_{2} / \mathrm{CO}, \mathrm{CO}_{2} / \mathrm{O}_{2}, \mathrm{O}_{2} /\left(\mathrm{CO}+\mathrm{CO}_{2}\right), \mathrm{O}_{2} / \mathrm{CO}, \mathrm{CO} / \mathrm{CH}_{4}$, and $\mathrm{O}_{2} / \mathrm{CH}_{4}$. By

325 weighted grey relational analysis, the quantitative coal spontaneous combustion indexes

326 were proposed, $\mathrm{CO}_{2} / \mathrm{CO}$ as the first index, $\mathrm{CO}_{2} / \mathrm{O}_{2}$, and $\mathrm{O}_{2} /\left(\mathrm{CO}+\mathrm{CO}_{2}\right)$ as the second index. 


\section{Statements and Declarations}

\section{CRediT authorship contribution statement}

Yang Li: Conceptualization, Methodology, Writing-original draft. Kai Wang: Validation, Writing-review \& editing. Yanni Zhang: Writing-review \& editing. Jun Deng: Writingreview \& editing.

\section{Ethical Approval}

Not applicable.

\section{Competing Interests}

The authors declare that they have no known competing financial interests or personal relationships that could have appeared to influence the work reported in this paper.

\section{Funding}

This work was supported by The Youth Innovation Team of Shaanxi Universities (21JP070), the National Natural Science Foundation of China (No. 52174199, 51974236), and the Key R\&D Program of Shaanxi Province (Grant No. 2021KW-11).

\section{Consent to Participate}

Not applicable.

\section{Consent to Publish}

The Author agrees to publication in "Environmental Science and Pollution Research" and also to publication of the article in English by Springer in Springer's corresponding English-language journal.

\section{Availability of data and materials}

The datasets used or analysed during the current study are available from the corresponding 
351 author on reasonable request. 


\section{References}

Brown, Charles E (1998) Coefficient of variation. Applied multivariate statistics in geohydrology and related sciences. Springer, Berlin, Heidelberg 155-157. https://doi.org/10.1002/9781118445112.stat 01496

Baris K, Kizgut S, Didari V (2012) Low-temperature oxidation of some Turkish coals. Fuel 93:423-432. https://doi.org/10.1016/j.fuel.2011.08.066

Deng J, Li B, Li ZB, Zhang Y, Guan XJ (2014a) Experiment study on gas indexes optimization for coal spontaneous combustion prediction. Coal Sci Technol 42(1):0253-2336 (in Chinese).

Deng J, Zhao JY, Zhang YN, Geng RL (2014b) Study on coal spontaneous combustion characteristic temperature of growth rate analysis. Procedia Eng 84:796-805. https://doi.org/10.1016/j.proeng.2014.10.498

Deng J, Xiao Y, Li QW, Lu JH, Wen H (2015) Experimental studies of spontaneous combustion and anaerobic cooling of coal. Fuel 157:261-269. https://doi.org/10.1016/j.fuel.2015.04.063

Deng J, Zhao JY, Xiao Y, Zhang YN, Huang AC, Shu CM (2017) Thermal analysis of the pyrolysis and oxidation behaviour of $1 / 3$ coking coal. J Therm Anal Calorim 129(3):1779-1786. https://doi.org/10.1007/s10973-017-6331-3

Deng J, Lei CK, Xiao Y, Cao K, Ma L, Wang WF et al (2018) Determination and prediction on "three zones" of coal spontaneous combustion in a gob of fully mechanized caving face. Fuel 211:458-470. https://doi.org/10.1016/j.fuel.2017.09.027

Fernandez-Anez N, Garcia-Torrent J (2019) Influence of particle size and density on the 
hot surface ignition of solid fuel layers. Fire Technol 55(1):175-191. https://doi.org/10.1007/s10694-018-0782-3

Fan HH, Wang K, Zhai XW, Hu LH (2021) Combustion kinetics and mechanism of preoxidized coal with different oxygen concentrations. ACS Omega 6(29):19170-19182. https://doi.org/10.1021/acsomega.1c02520

Glushkov DO, Kuznetsov GV, Strizhak PA (2015) Low-temperature ignition of coal particles in an airflow. Russ J Phys Chem B 9(2):242-249. https://doi.org/10.1134/S1990793115020050

Guo J, Wen H, Zheng XZ, Liu Y, Cheng XJ (2019a) A method for evaluating the spontaneous combustion of coal by monitoring various gases. Process Saf Environ Prot; 126:223-231. https://doi.org/10.1016/j.psep.2019.04.014

Guo XY, Deng CB, Zhang X, Wang YS (2019b) Formation law of hydrocarbon index gases during coal spontaneous combustion in an oxygen-poor environment. Energy Sources Part A 41(5):626-635. https://doi.org/10.1080/15567036.2018.1520345

He X, Oyadiji SO (2001) Application of coefficient of variation in reliability-based mechanical design and manufacture. J Mater Process Technol 119(1-3):374-378. https://doi.org/10.1016/S0924-0136(01)00938-4

Hu ZQ, Xia Q (2017) An integrated methodology for monitoring spontaneous combustion of coal waste dumps based on surface temperature detection. Appl. Therm Eng 122: 27-38. https://doi.org/10.1016/j.applthermaleng.2017.05.019

Honscha LC, Penteado JO, De Sá Gama V, Da Silva Bonifácio A, Aikawa P, et al (2021) Health impact assessment of air pollution in an area of the largest coal mine in Brazil. 
Jia XL, Wu JK, Lian CJ, Wang JJ, Rao JL, Feng RJ, Chen Y (2021) Investigating the effect of coal particle size on spontaneous combustion and oxidation characteristics of coal. Environ Sci Pollut Res 1-10. https://doi.org/10.1007/s11356-021-16929-1

Kong B, Li ZH, Yang YL, Liu Z, Yan DC (2017) A review on the mechanism, risk evaluation, and prevention of coal spontaneous combustion in China. Environ Sci Pollut Res 24(30):23453-23470. https://doi.org/10.1007/s11356-017-0209-6

Li ZH, Kong B, Wei AZ, Yang YL, Zhou YB, Zhang LZ (2016) Free radical reaction characteristics of coal low-temperature oxidation and its inhibition method. Environ Sci Pollut Res 23(23):23593-23605. https://doi.org/10.1007/s11356-016-7589-x

Liang YT, Zhang J, Wang LC, Luo HZ, Ren T (2019) Forecasting spontaneous combustion of coal in underground coal mines by index gases: A review. J Loss Prev Process Ind 57:208-222. https://doi.org/10.1016/j.jlp.2018.12.003

Luo L, Zhang H, Jiao AY, Jiang YZ, Liu JX, Jiang XM et al (2019) Study on the formation and dissipation mechanism of gas phase products during rapid pyrolysis of superfine pulverized coal in entrained flow reactor. Energy 173:985-994. https://doi.org/10.1016/j.energy.2019.02.128

Ma L, Zou L, Ren LF, Wang JI, Wang WF (2019) Reactivity and spontaneous combustion characteristics of high-sulphur coal during low-temperature oxidation. Int J Oil Gas Coal Technol 21(3):375-389. https://doi.org/10.1504/IJOGCT.2019.10021991

Ma L, Zou L, Ren LF, Chung YH, Zhang PY, Shu CM (2020) Prediction indexes and limiting parameters of coal spontaneous combustion in the Huainan mining area in 
China. Fuel 264:116883. https://doi.org/10.1016/j.fuel.2019.116883

Onifade M, Genc B (2020) A review of research on spontaneous combustion of coal. Int J Min Sci Technol 30(3):303-311. https://doi.org/10.1016/j.ijmst.2020.03.001

Qin YP, Liu W, Yang C, Fan ZZ, Wang LL, Jia GW (2012) Experimental study on oxygen consumption rate of residual coal in goaf. Safety Sci 50(4):787-791. https://doi.org/10.1016/j.ssci.2011.08.033

Qu LN (2018) A study on the prediction method of coal spontaneous combustion development period based on critical temperature. Environ Sci Pollut Res 25(35):35748-35760. https://doi.org/10.1007/s11356-018-3464-2

Rifella A, Setyawan D, Chun DH, Yoo J, Kim SD, Rhim YJ et al (2019) The effects of coal particle size on spontaneous combustion characteristics. Int J Coal Prep Util. https://doi.org/10.1080/19392699.2019.1622529.

Ren SJ, Wang CP, Xiao Y, Deng J, Tian Y, Song JJ et al (2020) Thermal properties of coal during low temperature oxidation using a grey correlation method. Fuel 260:116287. https://doi.org/10.1016/j.fuel.2019.116287

Song ZE, Kuenzer C (2014) Coal fires in China over the last decade: a comprehensive review. Int J Coal Geol 133:72-99. https://doi.org/10.1016/j.coal.2014.09.004

Shao ZL, Wang DM, Wang YM, Zhong XX, Tang XF, Hu XM (2015) Controlling coal fires using the three-phase foam and water mist techniques in the Anjialing Open Pit Mine, China. Nat Hazards 75(2):1833-1852. https://doi.org/10.1007/s11069-014$1401-3$

Taraba B, Michalec Z (2011) Effect of longwall face advance rate on spontaneous heating 
process in the gob area-CFD modelling. Fuel 90(8):2790-2797. https://doi.org/10.1016/j.fuel.2011.03.033

Wang SB, Luo KL, Wang X, Sun YZ (2016) Estimate of sulfur, arsenic, mercury, fluorine emissions due to spontaneous combustion of coal gangue: An important part of Chinese emission inventories. Environ Pollut 209:107-13. https://doi.org/10.1016/j.envpol.2015.11.026

Wen H, Guo J, Jin YF, Wang K, Zhang YT, Zheng XZ (2017a) Experimental study on the influence of different oxygen concentrations on coal spontaneous combustion characteristic parameters. Int J Oil Gas Coal Technol 16(2):187-202. https://doi.org/10.1504/IJOGCT.2017.086320

Wen H, Yu ZJ, Fan SX, Zhai XW, Liu WY (2017b) Prediction of spontaneous combustion potential of coal in the gob area using $\mathrm{CO}$ extreme concentration: a case study. Combust Sci Technol 189(10):1713-1727. https://doi.org/10.1080/00102202.2017.1327430

Wang K, Deng J, Zhang Y, Wang CP (2018a) Kinetics and mechanisms of coal oxidation mass gain phenomenon by TG-FTIR and in situ IR analysis. J Therm Anal Calorim 132(1):591-598. https://doi.org/10.1007/s10973-017-6916-x.

Wang JF, Zhang YL, Xue S, Wu JM, Tang YB, Chang LP (2018b) Assessment of spontaneous combustion status of coal based on relationships between oxygen consumption and gaseous product emissions. Fuel Process Technol 179:60-71. https://doi.org/10.1016/j.fuproc.2018.06.015

Wang CP, Zhao XY, Bai ZJ, Deng J, Shu CM, Zhang M (2021) Comprehensive index 
evaluation of the spontaneous combustion capability of different ranks of coal. Fuel 291:120087. https://doi.org/10.1016/j.fuel.2020.120087

Xiao Y, Li QW, Deng J, Shu CM, Wang W (2017) Experimental study on the corresponding relationship between the index gases and critical temperature for coal spontaneous

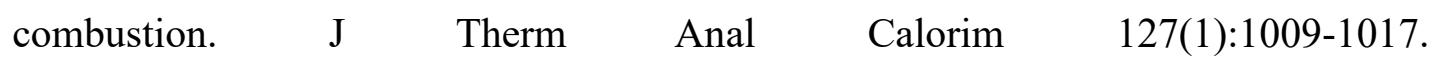
https://doi.org/10.1007/s10973-016-5770-6

Xu YS, Liu XW, Wang H, Zhang YF, Qi JX, Xu MH (2018) Investigation of simultaneously reducing the emission of ultrafine particulate matter and heavy metals by adding modified attapulgite during coal combustion. Energy Fuels 33(2):1518-1526. https://doi.org/10.1021/acs.energyfuels.8b03186

Yuan LM, Smith AC. CO and $\mathrm{CO}_{2}$ (2011) emissions from spontaneous heating of coal under different ventilation rates. Int $\mathrm{J}$ Coal Geol 88(1):24-30. https://doi.org/10.1016/j.coal.2011.07.004

Yi BJ, Zhang LQ, Huang F, Mao ZH, Zheng CG (2014a) Effect of $\mathrm{H}_{2} \mathrm{O}$ on the combustion characteristics of pulverized coal in $\mathrm{O}_{2} / \mathrm{CO}_{2}$ atmosphere. Appl. Energy 132:349-357. https://doi.org/10.1016/j.apenergy.2014.07.031

Yi BJ, Zhang LQ, Mao ZH, Huang F, Zheng CG (2014b) Effect of the particle size on combustion characteristics of pulverized coal in an $\mathrm{O}_{2} / \mathrm{CO}_{2}$ atmosphere. Fuel Process Technol 128:17-27. http://dx.doi.org/10.1016/j.fuproc2014.06.025

Zhu JF, He N, Li DJ (2012) The relationship between oxygen consumption rate and temperature during coal spontaneous combustion. Safety Sci 50(4):842-845. https://doi.org/10.1016/j.ssci.2011.08.023 
484

485

486

487

488

489

490

491

492

493

494

495

496

497

498

499

500

501

502

503

504

Zhang J, Ren T, Liang YT, Wang ZW (2016) A review on numerical solutions to selfheating of coal stockpile: Mechanism, theoretical basis, and variable study. Fuel 182:80-109. https://doi.org/10.1016/j.fue1.2016.05.087

Zhang YT, Shi XQ, Li YQ, Liu YR (2018) Characteristics of carbon monoxide production and oxidation kinetics during the decaying process of coal spontaneous combustion. Can J Chem Eng 96(8):1752-1761. https://doi.org/10.1002/cjce.23119

Zhang YN, Chen L, Deng J, Zhao JY, Li HT, Yang H (2019) Influence of granularity on thermal behaviour in the process of lignite spontaneous combustion. J Therm Anal Calorim 135(4):2247-2255. https://doi.org/10.1007/s10973-018-7440-3

Zhao JY, Deng J, Song JJ, Shu CM (2019) Effectiveness of a high-temperatureprogrammed experimental system in simulating particle size effects on hazardous gas emissions in bituminous coal. Safety Sci 115:353-361. https://doi.org/10.1016/j.ssci.2019.02.008

Zhao JY, Wang T, Deng J, Shu CM, Zeng Q, Guo T et al (2020) Microcharacteristic analysis of $\mathrm{CH} 4$ emissions under different conditions during coal spontaneous combustion with high-temperature oxidation and in situ FTIR. Energy 209:118494. https://doi.org/10.1016/j.energy.2020.118494

Zhai XW, Song BB, Wang B, Ma T, Ge H (2021) Study on the effect and mechanism of water immersion on the characteristic temperature during coal low-temperature oxidation. Nat Resour Res 1-13. https://doi.org/10.1007/s11053-021-09854-0 